\title{
Characterization of Wireless Channel Impact on Wireless Sensor Network Performance in Public Transportation Buses
}

\author{
Leire Azpilicueta, Peio López Iturri, Erik Aguirre, José Javier Astrain, Jesús Villadangos, Cristobal \\ Zubiri and Francisco Falcone, Senior Member, IEEE
}

\begin{abstract}
Wireless communications systems are growing rapidly during the last two decades and they are gaining a significant role for multiple communication tasks within public transportation buses. In this work, the impact of topology and morphology of different types of urban buses is analyzed with the aid of an in-house developed 3D Ray Launching code and compared with on-board measurements of a deployed Wireless Sensor Network. The presence of human beings has been taken into account, showing a significant influence in the signal attenuation in the case of considering persons. In addition, the statistical analysis of simulation results considering both large and small-scale fading has been performed, providing good agreement with statistics for typical indoor environments. In addition, a Wireless Sensor Network has been programmed and deployed within the buses in order to analyze topological impact with overall system performance, with the aim of minimizing the energy consumption as well as non-desired interference levels. The use of deterministic techniques destined to consider the inherent complexity of the buses can aid in wireless system planning in order to minimize power consumption and increase overall system capacity.
\end{abstract}

Index Terms-Indoor propagation, ray launching, urban buses, wireless sensor network.

\section{I.INTRODUCTION}

$\mathrm{T}$ HE URBAN bus is used every day by millions of people in cities around the world. During the last two decades, it has become one of the most extended public transportation systems. With the improvement of living standards of city residents, the development of information technologies applying to cities to improve bus service levels and improve the efficiency of bus operation became highly necessary. The main objectives are to achieve a safe, accurate and efficient transportation system in cities. It is also aimed helping elder or disabled people for independent travels in the urban buses. Because of the continuous movement of the buses, wireless

Leire Azpilicueta, Peio López, Erik Aguirre, Cristobal Zubiri and Francisco Falcone are with the Electrical and Electronic Engineering Dept, Public University of Navarre, Pamplona, Navarra, Spain

José Javier Astrain and Jesús Villadangos are with the Mathematical Engineering and Computer Science Dept., Public University of Navarre, Pamplona, Navarra, Spain

(phone: +34-948-169741; fax: +34-948-160720; e-mail: francisco.falcone@unavarra.es). communications networks have been increasingly used to support these services of public transportation.

In the literature, different wireless technologies have been used to achieve the real time location of urban buses and collect traffic information, with the aim of informing of the waiting time for passengers or the occurrence of incidences. Innovative technologies that give information about the conditions of the road have been developed based in WLAN networks, in many cases as Mobile ad-hoc Networks (MANET) or Vehicular ad-hoc Networks (VANET) [1] in its variant for vehicles. These and other wireless technologies are combined to create Intelligent Transport System (ITS), which allow an intelligent management of roads and also results in Advanced Public Transport Systems (APTS) [2] that estimate the arrival time of buses, offering an improved service. In addition, Wireless Sensor Networks (WSNs) offer the potential to significantly improve the efficiency of existing transportations systems [3-5].

Moreover, several applications have been designed for urban buses to help blind and disabled people, like the MobiPlus system [6], an intelligent wireless bus-station interactive system with the integration of multi-wireless techniques (RFID, WiFi, ZigBee and GPS). In [7] the U-Bus system is proposed based on WSN for blind people recognition and communication with the bus. The RAMPE system [8] also describes a system for the mobility and autonomy of blind people in public transports. It can be also employed for elder, disabled or wheelchair passengers. Another project with the aim of helping blind people for independent navigation in urban transport is presented in [9] using WSNs based on ZigBee technology.

With the aim of enhancing the performance of these applications, the assessment of radio wave propagation within the indoor environment or urban buses is compulsory. Different simulation methods can be found in the literature to obtain propagation estimations and characterization of the radio channel for intra-vehicle communications. One of the key elements for wireless system planning is coverage/capacity analysis. Typically, statistical characterization of the radio channel has been obtained performing measurements within vehicles such as a car [1012], a commercial aircraft cabin [13-17] or trains [18]. These methods usually define a simple and not highly accurate radio channel, with low computational cost but limited accuracy. On the other hand, deterministic methods, which are based on 
numerical approaches to the resolution of Maxwell's equations, improve strongly the accuracy and precision of the simulation results, obtaining reliable estimations of the propagation. Among these methods there are the Finite Difference Time Domain (FDTD) method and the Method of Moments (MoM) [19]. But for the simulation of a complex intra-vehicular environment, such as the public buses, they can be highly time-consuming due to the high computational cost. It is necessary therefore to apply alternative simulation methods to finally obtain estimations in a reasonable way. Deterministic methods based on Geometric Optics (GO) and Geometrical Theory of Diffraction (GTD) offer an adequate trade-off between accuracy and calculation time [20]. The Ray Tracing method combined with uniform theory of diffraction (UTD) is most frequently applied to radio coverage prediction [21-24].

In this work, an in-depth propagation study within two different types of public buses is presented, emulating an operating WSN. This is an important task due to the occurrence of significant multipath propagation in this type of environments because of the major metallic mass of the vehicles. The appropriate election of the emplacement of the communication nodes, the adequate election of the RF frequency to use and the adequate selection of the topology of the WSN may provide better results on communication efficiency, reduce interference and therefore minimize the energy consumption of the nodes. For such reason, we tackle in this work the radio planning in different types of urban buses in order to optimize the overall systems, minimizing power consumption as well as non-desired interference levels and collisions, which are critical parameters in WSNs due to their strict energy constraints.

This paper aims characterizing the effect of radio wave propagation phenomena in on-board transceivers in order to assess the impact of the morphology of the different buses as well as the topology of the wireless system, in order to optimize system performance. The simulation of radio propagation within the vehicles has been carried out by means of an in-house three-dimensional ray-tracing method, which is a novel method for analyzing the radio channel inside public transportation buses. A schematic view of the followed procedure has been shown in Fig. 1. Firstly, simulations of the considered scenarios have been done with the Ray launching approach, for radio planning purposes. In addition, the Ray launching technique has been validated with real measurements and statistical analysis. With these results, coverage/capacity analysis has been done before the deployment of a WSN within the buses. After that, a WSN has been deployed with the optimal positions of the receivers, and the system evaluation has been done, leading to the optimal behavior of the system.

The rest of the paper is organized as follows: section II is devoted to describe both the in-house developed 3D Ray Launching algorithm, and the different considered scenarios. Section III shows simulation results with the presence of human beings inside the vehicle and without them. Section IV describes the statistical analysis of simulation results, which agree with statistics found in the literature for typical indoor environments. In section $\mathrm{V}$, RF measurements validate simulation results of a WSN focusing in localizing multiple transceivers within the buses. Finally, conclusions and references end this paper.

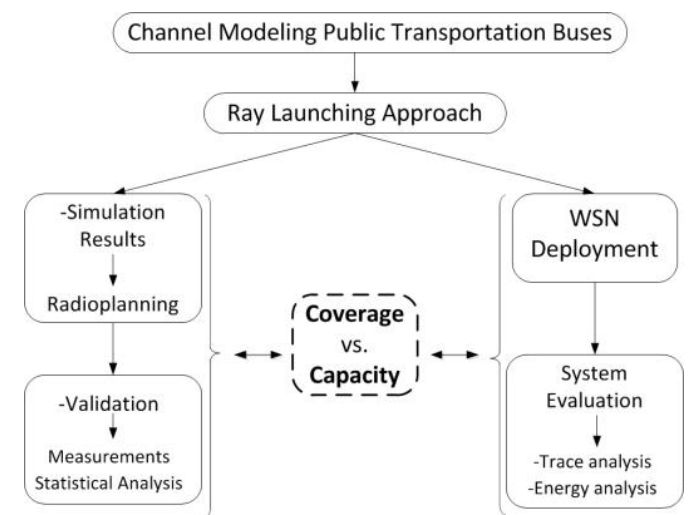

Fig. 1. Schematic representation of the organization of the paper.

\section{RAY LAUNCHING APPROACH AND DEFINITION OF THE VEHICLES CONSIDERED}

The initial step is to define the appropriate simulation technique in order to analyze a complex environment such as the indoor of an urban bus. A 3D Ray Launching (RL) algorithm has been implemented in-house based on Geometrical Optics (GO) and Geometrical Theory of Diffraction (GTD). A detailed description of the proposed approach can be found in [25]. In addition, different applications of this algorithm are shown in the literature, such as the analysis of wireless propagation in closed environments [26-29], interference analysis [30] or electromagnetic dosimetry evaluation in wireless systems [31]. RL techniques are based on identifying a single point on the wave front of the radiated wave with a ray that propagates along the space following a combination of optic and electromagnetic theories.

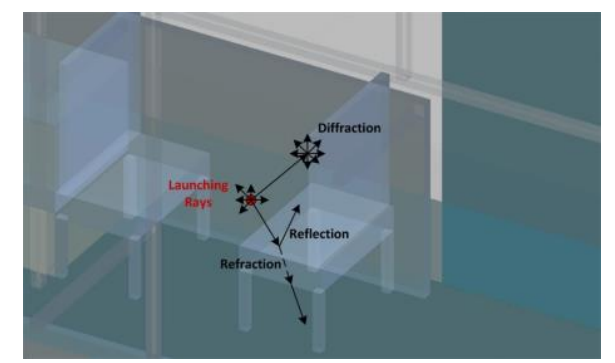

Fig. 2. Schematic representation of the principle of operation of the in-house developed 3D Ray Launching algorithm.

The in-house RL algorithm is implemented threedimensionally, with angular resolution (horizontal and vertical planes) in a predefined solid angle that takes into account the radiation diagram of the transceivers sources. Spatial resolution when computing ray interaction is given by a uniform hexahedral mesh with cuboids of a given lateral dimension. A finite sample of the possible directions of the propagation from the transmitter is chosen and a ray is launched for each such direction. When the ray impacts with an obstacle, reflection, transmission and diffraction will occur, depending on the geometry and the electric properties of the object, as is depicted in Fig. 2. 
Fig. 3 (left) shows the three types of urban buses which have been employed for the setup of measurements. Fig. 3 (right) shows the internal distribution of one of the articulated vehicles, including seat and handhold distribution.
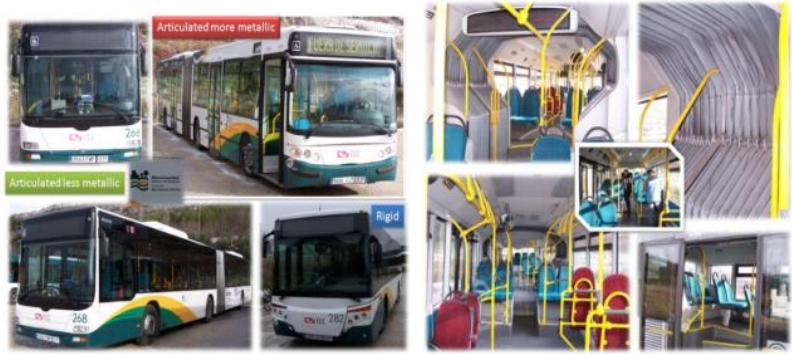

Fig. 3. Vehicles used on the experimentation (left) and internal distribution of an articulated bus (right).

As it can be observed in Fig. 3 (right), the buses considered include red seats reserved for individuals with disabilities, which have different dimensions or are prepared to engage wheelchairs or prams. The remaining seats, turquoise blue, are employed by the rest of passengers. The simulation scenarios implemented for calculation by the 3D Ray Launching code corresponds to the real buses shown in Fig. 3. A view of the vehicles model developed for simulation is depicted in Fig. 4, which corresponds with the articulated more metallic urban bus (top) and the rigid bus (bottom).

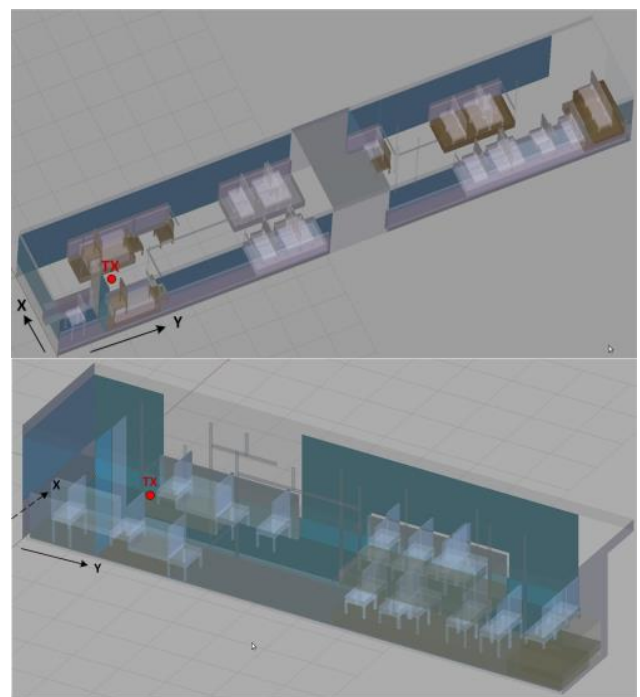

Fig. 4. Simulation scenarios developed for calculation by means of in-house developed 3D RL code: Articulated (top) and Rigid buses (bottom).

The articulated bus has two variants which correspond with two different structure materials of the vehicle. The first one has walls, ceiling and floor made of metal, and the other is a new model, lighter, with less metallic parts and more plastic structures. The rigid bus has only metallic structure. All the elements within the different models of buses have been taken into account, like the different dimensions and distribution of seats, different heights, the metallic handholds and the bellows for the articulated bus model. The material parameters used in the simulation models, are defined in Table I [32].

In addition, two new models of the articulated urban bus with more metallic content and the rigid bus have been created with the random presence of several persons inside them. A simplified human body model, including the dispersive nature of material organs, skin, muscle, bones and other elements has been implemented within the in-house developed 3D ray launching code [33]. Fig. 5 depicts the two scenarios created with several human body models inside them, which have been simulated and compared with the models without persons. In section III.B it is shown that the impact of persons within vehicles has a great influence in radio wave propagation and it is necessary to take them into account for the implementation of wireless systems inside vehicles.

TABLE I

MATERIAL PROPERTIES IN THE RAY LAUNCHING SiMULATION

\begin{tabular}{ccccc}
\hline \hline Parameters & Air & Aluminum & Glass & Polycarbonate \\
\hline Permittivity $\left(\varepsilon_{\mathrm{r}}\right)$ & 1 & 4.5 & 6.06 & 3 \\
Conductivity $(\sigma)[\mathrm{S} / \mathrm{m}]$ & 0 & $4 * 10^{7}$ & $10^{-12}$ & 0.2 \\
\hline \hline
\end{tabular}

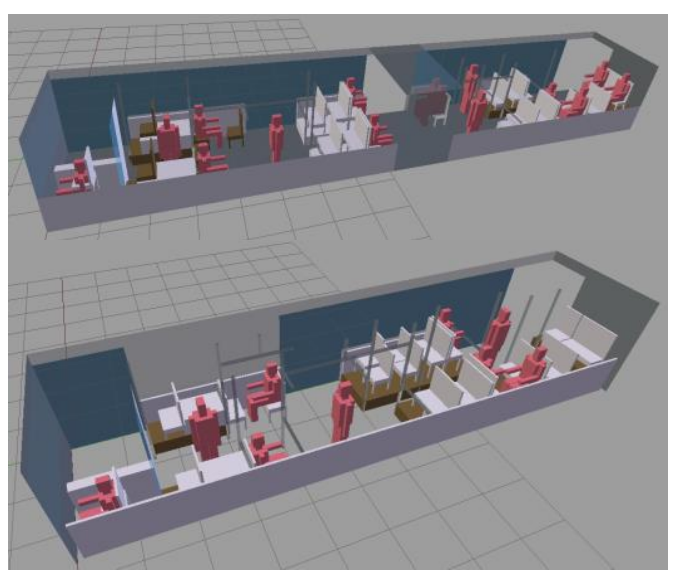

Fig. 5. Simulation scenarios developed with the random presence of several persons inside them for calculation by means of the in-house developed 3D Ray Launching code: Articulated (top) and Rigid (bottom) buses, respectively.

\section{SIMULATION RESULTS}

In order to provide radioplanning estimations within the indoor urban bus scenarios, different wireless channel simulations have been obtained. Simulations have been performed for the metallic articulated bus and rigid bus (with and without the presence of persons), with the transmitter antenna placed at the point $(\mathrm{X}=1.35 \mathrm{~m}, \mathrm{Y}=2.03 \mathrm{~m}, \mathrm{Z}=1.10 \mathrm{~m})$ (Case I), which is depicted with a red point in Fig. 4. A Case II has been also considered with the transmitter antenna placed at the point $(\mathrm{X}=1.35 \mathrm{~m}, \mathrm{Y}=13.72 \mathrm{~m}, \mathrm{Z}=1.10 \mathrm{~m})$. The simulation parameters are shown in Table II. The transmitter and receiver antennas are omnidirectional, with $5 \mathrm{dBi}$ gain respectively. The resolution of the cuboids and the number of reflections has been set to $10 \mathrm{~cm}$ and 6 , respectively, to balance accuracy with simulation time. Each cuboid is considered as a receiver. It should be noted that the number of reflections and the angular resolution has been chosen as a result of the convergence analysis of the algorithm [25]. Diffraction phenomena have also been taken into account in the simulations due to its significant effect in this propagation environment. The angular resolution of diffracted rays has been chosen as a result of a convergence analysis, taking into account results accuracy and computational time of simulations. Parameters considered in the ray launching simulation are a $2.4 \mathrm{GHz}$ frequency, a 
transmission power of $-10 \mathrm{dBm}$, an antenna gain of $5 \mathrm{dBi}$, a horizontal and vertical planes angle resolution $(\Delta \Phi)$ of one degree, 6 reflections, an angular resolution diffracted rays of nine degrees and one reflection of diffracted rays.

\section{A. Without the presence of human body models}

As a first step, the comparison between several empirical propagation models versus the in-house 3D Ray Launching approach has been obtained. Fig. 6 shows the estimated received power for different propagation models for the metallic articulated bus along the $\mathrm{Y}$-axis. It can be seen that the 3D RL approach exhibits more variations than empirical models, which follow the trend of the RL model but don't take into account any obstacles in their path. To gain insight on the estimated received power, Fig.7 shows the bi-dimensional plane of received power following the ITU-R P-1238 empirical model. It can be seen that the received power decreases linearly along the metallic articulated bus. This is due to the fact that this model does not take into account obstacles, such as seats, handholds and other elements that significantly impact radio wave propagation. Therefore, it is compulsory the use of deterministic methods such as 3D RL which lead to more precise results with affordable computational time.

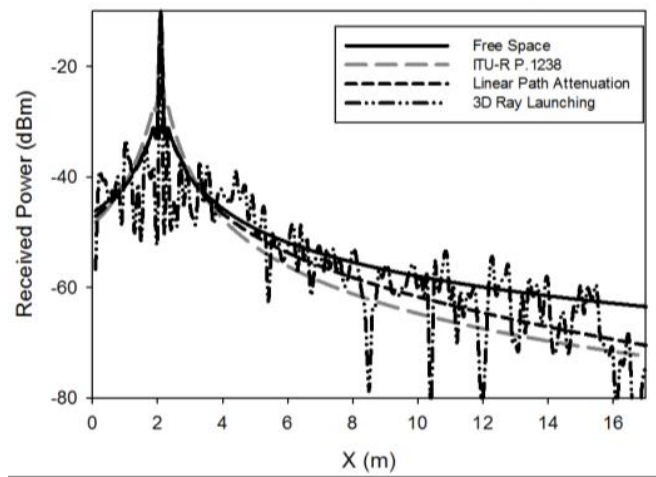

Fig. 6. Estimated received power for different empirical propagation models and the 3D Ray Launching approach.

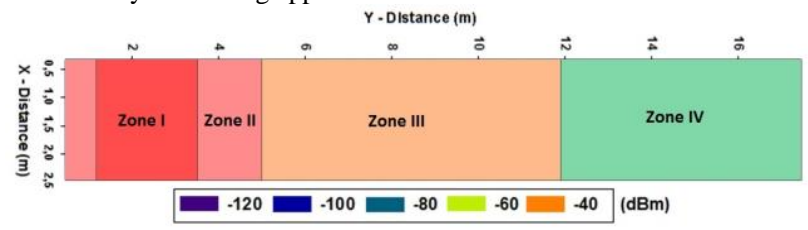

Fig. 7. Received power $(\mathrm{dBm})$ within the metallic articulated bus for $2.4 \mathrm{GHz}$ frequency for the empirical model ITU-R P.1238.

Fig. 8 shows simulation results obtained by means of inhouse developed 3D Ray Launching algorithm for received power for $2.4 \mathrm{GHz}$ for the metallic articulated bus and the rigid bus for Case I. Power results are shown at a 2D longitudinal cut plane of 0.8 meters in height, although simulation results have been obtained for the complete simulation scenario. This height has been chosen to emulate the typical height in which a seated person could use a wireless device. As it can be seen from the previous results, received power levels strongly depend on the location of the transceivers, a direct consequence of the impact of topology and morphology in an indoor vehicular environment. Elements such as passenger seats produce power absorption as well as scattering, leading to increased losses. Moreover, received power decreases with distance, leading to lower values of power in the final part of the articulated bus.

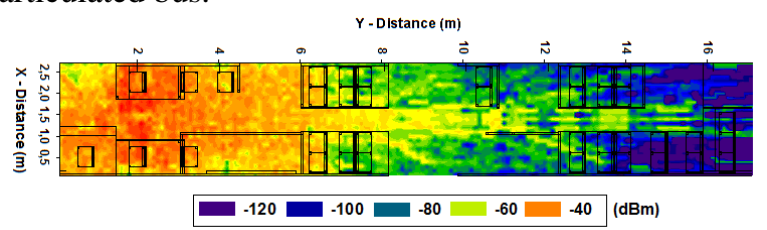

(a)

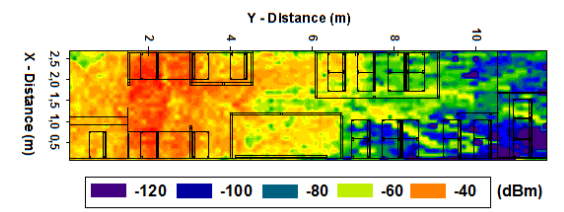

(b)

Fig. 8. Received Power (dBm) within the different models of the buses for $2.4 \mathrm{GHz}$ frequency with the transmitter antenna placed at the point $(X=1.35 \mathrm{~m}$, $\mathrm{Y}=2.03 \mathrm{~m}, \mathrm{Z}=1.10 \mathrm{~m}$ ) (a) Metallic articulated bus. (b) Rigid bus.

Fig. 9 shows the different zones of estimated received power extracted from the data of Fig. 8. It can be seen that the morphology and the topology of the different buses plays an important role in the radio planning task, obtaining different values of the mean received power depending of the obstacle density of the different zones. Table II and Table III show the different values of power mean with its standard deviation and the obstacle density of the zone considered. It is observed that obstacle density has great influence in received power, but it is also relevant to consider the area of the considered zone and the distance from the transmitter of each zone.

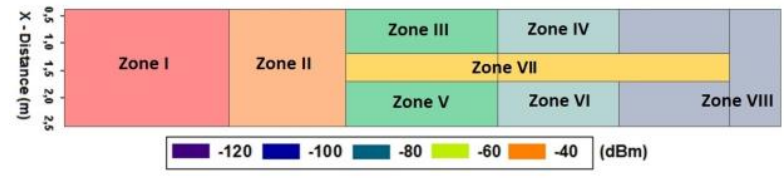

(a)

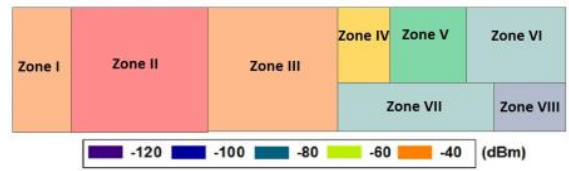

(b)

Fig. 9. Received Power $(\mathrm{dBm})$ divided by zones within the different models of buses for $2.4 \mathrm{GHz}$ frequency with the transmitter antenna placed at the point ( $\mathrm{X}=1.35 \mathrm{~m}, \mathrm{Y}=2.03 \mathrm{~m}, \mathrm{Z}=1.10 \mathrm{~m}$ ) (a) Metallic articulated bus. (b) Rigid bus.

To gain insight into the influence that the morphology of the scenario may have in radio wave propagation, a Case II has been considered placing the transmitter antenna at the point $(\mathrm{X}=1.35 \mathrm{~m}, \mathrm{Y}=13.72 \mathrm{~m}, \mathrm{Z}=1.10 \mathrm{~m})$. Bi-dimensional planes of estimated received power have been obtained for the same height that Case I and they are shown in Fig. 10. It is observed that, when the position of the transmitter antenna changes, the complete plane of estimated received power also changes, depending of the position of the obstacles and, as stated above, of the obstacle density and the distance from the transmitter. Fig. 11 shows the same planes divided in different zones according to the mean received power, which can be very useful for radio planning purposes, with the associated tables 
(Tables IV and V), which present the data associated with the graphs.

TABLE II

\begin{tabular}{ccccc}
\hline \hline Zone & $\begin{array}{c}\text { Area } \\
\left(\mathbf{m}^{\mathbf{2}}\right)\end{array}$ & $\begin{array}{c}\text { Power } \\
\text { Mean } \\
(\mathbf{d B m})\end{array}$ & $\begin{array}{c}\text { Standard } \\
\text { Deviation } \\
(\mathbf{d B})\end{array}$ & $\begin{array}{c}\text { Obstacles } \\
\text { Density } \\
(\boldsymbol{\%})\end{array}$ \\
\hline \hline I & 8.28 & -44.61 & 3.447 & 23.84 \\
\hline II & 7.83 & -53.54 & 4.59 & 14.15 \\
\hline III & 3.96 & -74.05 & 3.765 & 0.51 \\
\hline IV & 3.02 & -78.82 & 3.059 & 6.29 \\
\hline V & 3.96 & -73.51 & 3.283 & 6.28 \\
\hline VI & 3.02 & -80.22 & 2.915 & 14.23 \\
\hline VII & 4.55 & -81.25 & 9.34 & 0 \\
\hline VIII & 8.88 & -136.77 & 44.98 & 38.6 \\
\hline \hline
\end{tabular}

TABLE III

\begin{tabular}{ccccc}
\hline \hline Zone & $\begin{array}{c}\text { Area } \\
\left(\mathbf{m}^{2}\right)\end{array}$ & $\begin{array}{c}\text { Power } \\
\text { Mean } \\
(\mathbf{d B m})\end{array}$ & $\begin{array}{c}\text { Standard } \\
\text { Deviation } \\
(\mathbf{d B})\end{array}$ & $\begin{array}{c}\text { Obstacles } \\
\text { Density } \\
(\boldsymbol{\%})\end{array}$ \\
\hline \hline I & 4.05 & -50.89 & 2.81 & 10.37 \\
\hline II & 6.75 & -43.62 & 5.38 & 21.48 \\
\hline III & 8.10 & -58.17 & 4.39 & 6.91 \\
\hline IV & 1.70 & -74.87 & 2.82 & 34.07 \\
\hline V & 2.55 & -80.68 & 5.05 & 0.95 \\
\hline VI & 3.74 & -98.67 & 10.83 & 14.6 \\
\hline VII & 3 & -74.00 & 7.86 & 32.41 \\
\hline VIII & 1.7 & -84.88 & 7.24 & 60.62 \\
\hline \hline
\end{tabular}

From these results, it is shown that received power in different points of the scenarios depends greatly of the position of the transmitter, the obstacle density of the different zones and the different material properties of the obstacles. It is observed that multipath propagation is one of the most important phenomena in these types of environments, with a lot of metallic elements. Due to this fact, it is highly important to consider deterministic modelling such as RL for radio planning purposes, which permits to achieve a precise estimation of received power levels in the different parts of the transportation buses, for each transmitter antenna desired position, considering all the elements within the scenario. In terms of coverage, this analysis could lead to the optimal configuration of a WSN within the buses

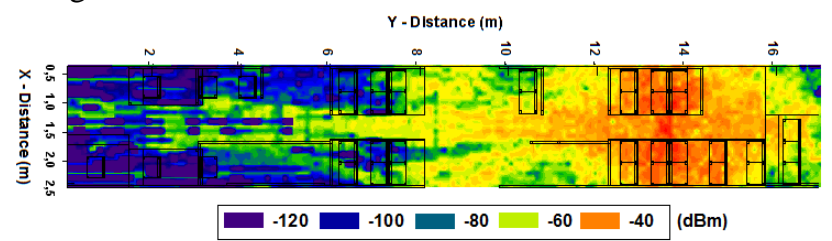

(a)

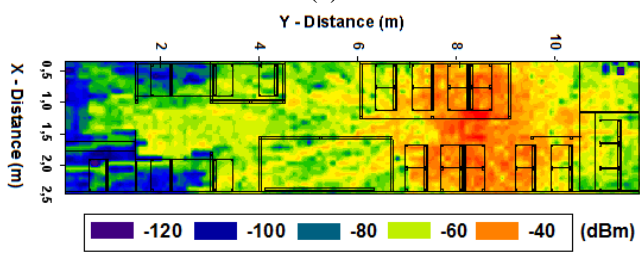

(b)

Fig. 10. Received Power $(\mathrm{dBm})$ within the different models of the buses for $2.4 \mathrm{GHz}$ frequency with the transmitter antenna placed at the point $(X=1.35 \mathrm{~m}$, $\mathrm{Y}=13.72 \mathrm{~m}, \mathrm{Z}=1.10 \mathrm{~m}$ ) (a) Metallic articulated bus. (b) Rigid bus.

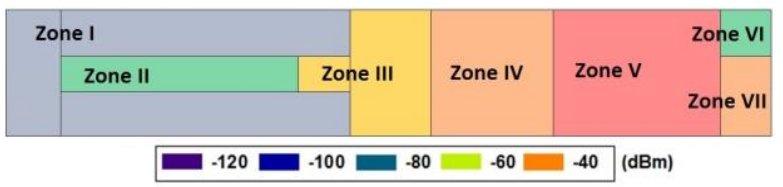

(a)

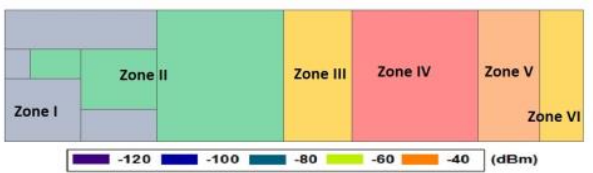

(b)

Fig. 11. Received Power ( $\mathrm{dBm})$ divided by zones within the different models of the buses for $2.4 \mathrm{GHz}$ frequency with the transmitter antenna placed at point (X=1.35m, Y=13.72m, Z=1.10m) (a) Metallic articulated and (b) Rigid buses.

TABLE IV

\begin{tabular}{ccccc}
\hline \hline \multicolumn{5}{c}{ CASE II Metallic articulated bus } \\
\hline \hline Zone & $\begin{array}{c}\text { Area } \\
\left(\mathbf{m}^{2}\right)\end{array}$ & $\begin{array}{c}\text { Power } \\
\text { Mean } \\
(\mathbf{d B m})\end{array}$ & $\begin{array}{c}\text { Standard } \\
\text { Deviation } \\
(\mathbf{d B})\end{array}$ & $\begin{array}{c}\text { Obstacles } \\
\text { Density } \\
(\mathbf{\%})\end{array}$ \\
\hline \hline I & 17.42 & -107.88 & 32.63 & 21.59 \\
\hline II & 2.55 & -91.42 & 58.34 & 3.92 \\
\hline III & 6.49 & -60.67 & 3.16 & 0.92 \\
\hline IV & 6.48 & -55.66 & 3.98 & 5.63 \\
\hline V & 9.99 & -43.95 & 5.88 & 24.07 \\
\hline VI & 1.62 & -68.35 & 12.89 & 0 \\
\hline VII & 1.84 & -59.59 & 3.69 & 85 \\
\hline \hline
\end{tabular}

TABLE V

\begin{tabular}{ccccc}
\hline \hline Zone & $\begin{array}{c}\text { Area } \\
\left(\mathbf{m}^{\mathbf{2}}\right)\end{array}$ & $\begin{array}{c}\text { Power } \\
\text { Mean } \\
(\mathbf{d B m})\end{array}$ & $\begin{array}{c}\text { Standard } \\
\text { Deviation } \\
(\mathbf{d B})\end{array}$ & $\begin{array}{c}\text { Obstacles } \\
\text { Density } \\
(\mathbf{\%})\end{array}$ \\
\hline \hline I & 5.85 & -81.83 & 4.33 & 29.66 \\
\hline II & 9 & -62.72 & 1.45 & 4.46 \\
\hline III & 4.05 & -58.11 & 1.76 & 10.12 \\
\hline IV & 6.75 & -42.57 & 3.95 & 21.14 \\
\hline V & 2.7 & -53.24 & 2.63 & 4.52 \\
\hline VI & 3.24 & -61.96 & 4.05 & 46.12 \\
\hline \hline
\end{tabular}

As stated before, the fundamental radio electric phenomenon in this type of vehicle indoor environment is given by multipath propagation. To illustrate this fact, the power delay profile for the point $(X=1.4 \mathrm{~m}, Y=4 \mathrm{~m}, \mathrm{Z}=0.8 \mathrm{~m})$ in the metallic articulated bus is depicted in Fig. 12, exhibiting echoes in a time span of 0 to $180 \mathrm{~ns}$. Time dispersion varies widely in a mobile radio channel depending on the geometrical position relationships among the transmitter, the receiver and the surrounding physical environment. Due to this fact, another parameter that can grossly quantify the multipath channel is the delay spread, which shows the effects of dispersion and is depicted in Fig. 13 for the metallic articulated bus and the rigid bus. The delay spread has been calculated using as threshold the noise floor, with a value of $-120 \mathrm{dBm}$.

From Fig. 13 it can be seen that the multipath phenomenon is very different in both vehicles. The morphology and topology of the buses has a great influence in the time dispersion of the channel. It is observed that in the metallic articulated bus, the delay spread is higher in the areas closest to the transmitter antenna and is lower in the final part of the vehicle because the radiation power in this part is smaller due to the larger distance. However, in the rigid bus the differences between 
both sides of the vehicle are not as significant as the longer bus. This is due to the metallic bellow which is situated in the central part of the metallic articulated bus, which has a great influence in the behavior of multipath propagation inside the vehicles.

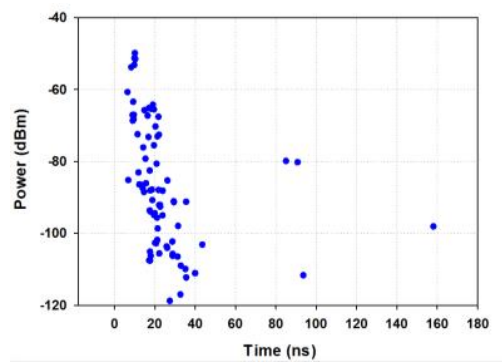

Fig. 12. Power Delay Profile at a given cuboid, located at the point $(X=1.4 \mathrm{~m}$, $\mathrm{Y}=4 \mathrm{~m}, \mathrm{Z}=0.8 \mathrm{~m})$ in the indoor metallic articulated bus.

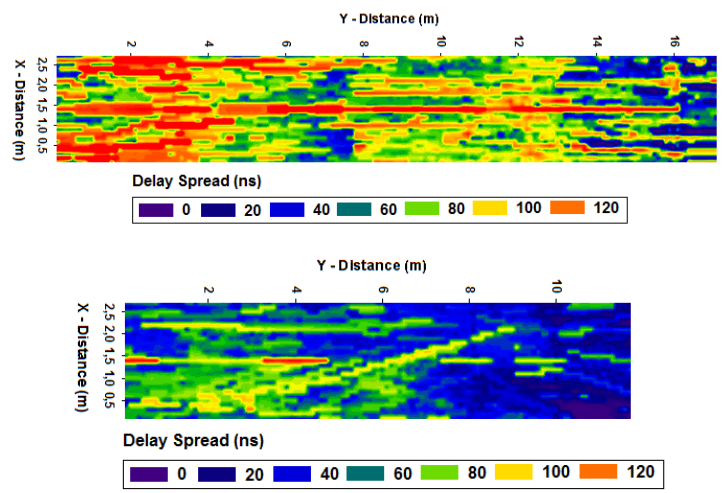

Fig. 13. Delay Spread estimation at a bi-dimensional plane of $0.8 \mathrm{~m}$ height (top) Metallic articulated bus. (bottom) Rigid bus.

\section{B. With the presence of human body models}

Simulations with the random presence of persons inside the vehicles have been done in order to analyze the impact of the human bodies in the characterization of the channel for the development of On-Body Area Networks or WSNs within the public transportation buses. For that purpose, the vehicles modeled with persons depicted in Fig. 5 have been simulated with the same simulation parameters described in Section III. Fig. 14 and Fig. 15 show simulation results for the articulated more metallic bus (Fig. 14) and for the rigid bus (Fig. 15). In both figures, three cases are shown, Case I and Case II are the estimated received power for the bi-dimensional planes of $0.8 \mathrm{~m}$ height without persons inside the vehicles (Case I) and with persons (Case II). The third case represents the difference between the two previous cases, which represents the spatial samples which are affected by the presence of persons. From both figures, it is observed that the presence of persons (Case II) has a great impact in the estimated received power, having a widely fading channel in some spatial samples in this case than the case without persons. Case III shows the comparison between the two previous cases, showing that the presence of persons has a significant influence in the characterization of the channel. Accordingly, it is highly important to take into account the presence of human bodies within these types of vehicles.

From these results it can be concluded that the number of individuals is a fundamental parameter for the power distribution inside a bus. Therefore, two more simulations have been considered including more people, thus, starting from the original cases where the human occupation rate was approximately of the $3 \%$, an occupation of $6.5 \%$ and $9.8 \%$ is reached for two kinds of buses.

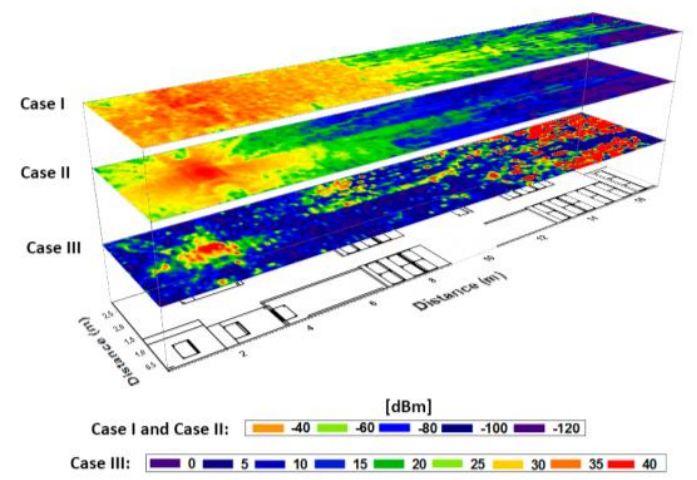

Fig. 14. Comparison of Received Power (dBm) for the bi-dimensional plane of $0.8 \mathrm{~m}$ height for the metallic articulated bus without persons (Case I), with persons (Case II) and difference between them (Case III).

The results show that the deviation from the situation of empty vehicle grows with the inclusion of more human body models into the scenario. In the case of rigid bus the low occupation scenario (3\%) gives an error of $5 \mathrm{~dB}$ and a Standard Deviation $(\mathrm{SD})$ of $21 \mathrm{~dB}$ while the high occupation reach an error level of $7.8 \mathrm{~dB}$ and a standard deviation of $26.6 \mathrm{~dB}$. The occupational difference is especially noticeable when the articulated bus is considered, with values for the three situations (in occupational ascendant order) of $9.3 \mathrm{~dB}(28.5 \mathrm{~dB}$ $\mathrm{SD}), 11.8 \mathrm{~dB}(33.3 \mathrm{~dB} \mathrm{SD})$ and $14 \mathrm{~dB}(38.41 \mathrm{~dB} \mathrm{SD})$. The fact that the bus is longer together with a larger absolute number of people lead to higher deviations comparing with empty buses.

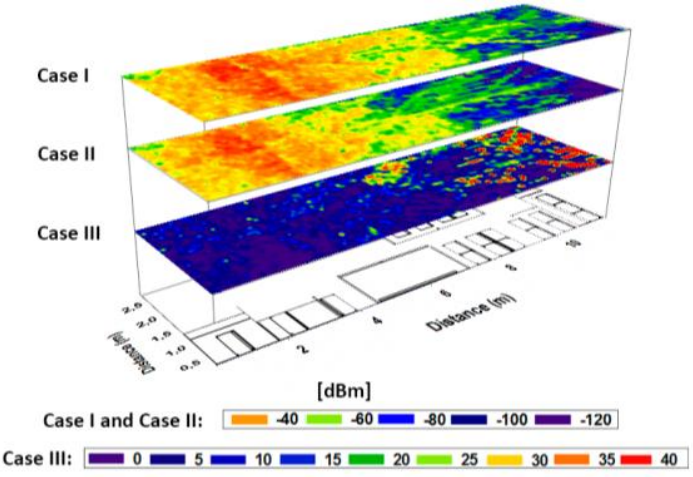

Fig. 15. Comparison of estimated Received Power $(\mathrm{dBm})$ for the bidimensional plane of $0.8 \mathrm{~m}$ height for the rigid bus without persons (Case I), with persons (Case II) and difference between them (Case III).

\section{STATISTICAL ANALYSIS}

\section{A. Path Loss Model}

A widely used simple indoor path loss model is the oneslope model, based on the following expression [34]:

$$
P L(d)=\overline{P L}(d)+\mathrm{X}_{\sigma}=\overline{P L}\left(d_{0}\right)+10 n \log _{10}\left(\frac{d}{d_{0}}\right)+\mathrm{X}_{\sigma}
$$

where $\overline{P L}\left(d_{0}\right)$ is the intercept, $d$ is the distance from the transmitter to the receiver in meters, and $n$ is the path loss exponent dependent on the specific propagation environment indicating the rate at which $P L$ increases with distance. In free 
space propagation, $n$ equals $2 . \mathrm{X}_{\sigma}$ denotes shadow fading with standard deviation $\sigma$. The bars in eq. 1.4 denote the ensemble average of all possible path loss values for a given value of $d$.

Estimated path loss values have been calculated in the considered scenarios and compared with the lognormal distribution. From the results of received power estimated for the whole scenarios in the previous section, path loss can be predicted for each spatial point of the environment appliying:

$$
P L(d)[d B]=P_{t}[d B m]-P_{r}[d B m]
$$

with the antenna gains included in $P_{t}[\mathrm{dBm}]$ and $P_{r}[\mathrm{dBm}]$. The spatial sampling with the $3 \mathrm{D}$ ray launching technique has been set to cuboids of $10 \mathrm{~cm}$, taking into account accuracy results and computational time of simulations. Fig. 16 shows the scatter plot of the simulated values path loss for a height of $1.1 \mathrm{~m}$ with respect to the transmitter-receiver separation in logarithmic scale. Additionally, the linear regression line, resulting from a minimum mean square error (MMSE) analysis, is shown, which is expressed as

$$
P L(d)=40.3+17.79 \log _{10}(d) ; \sigma=10.22 d B
$$

The corresponding path loss exponent is $\mathrm{n}=1.779$ with a standard deviation $\sigma=10.22 \mathrm{~dB}$. Accordingly, $\mathrm{n}$ is slightly smaller than for free space propagation and lies in the range of values found for indoor radio wave propagation in office environments [34-36]. It can be found in the literature [34] that depending of the surrounding environment, $\mathrm{n}$ varies between 1.6 and 3.3 and $\sigma$ between 3 and $14 \mathrm{~dB}$.

From Fig. 16 it can be seen that the log-normal distribution describes the random shadowing effects in the considered scenario. This phenomenon is referred to as the large-scale fading or log-normal shadowing which is caused for the slow variation in mean signal level. The considered distance for the receivers to analyze this effect has been set to the selected cuboids size, which is equivalent to three-quarters wavelength.

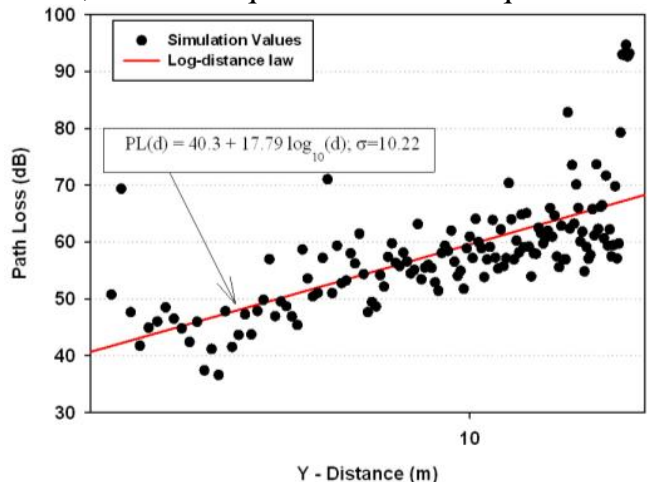

Fig. 16. Path loss versus Tx-Rx separation with linear regression fit.

\section{B.Smalle-scale Fading Statistics}

In order to verify the behavior of fast fading of the received field at different points of the considered scenario, local statistics have been calculated with the power delay profiles. Fig. 17 represents the variation of received power along the Yaxis, for $\mathrm{X}=1.35 \mathrm{~m}$ and $\mathrm{Z}=1.1 \mathrm{~m}$, for the metallic articulated bus depicted in Fig. 4a. It is observed a great variability in the received power and it can be seen that the median value of the signal strength is monotonous decreasing with distance. The median level is subject to two major variations. One is largescale signal variations, which it has been found to be normally distributed [36], as it is previously shown in Fig. 16. The second variation is the small-scale variation due to the vector combination of multiple rays arriving at the local vicinity of the portable communications antenna. The small-scale variation which has been analyzed in the channel is referred to as flat fading, based on multipath delay spread which causes that the strength of the received signal changes with time [34]. The small-scale variation for narrowband signals is distributed according to Rayleigh statistics [34, 36]. An analysis of the small-scale fading within the metallic articulated bus has been made. The selected points for the analysis are the four points depicted with a circle in Fig. 17. The small-scale fading has been analyzed with the power delay profiles for these four spatial samples, each of them with a three-quarters wavelength distance. Fig. 18 shows the variability of signal amplitude with time for the selected points. The separation of samples in wavelength is in agreement with the literature for small-scale analysis for indoor environments [37-38].

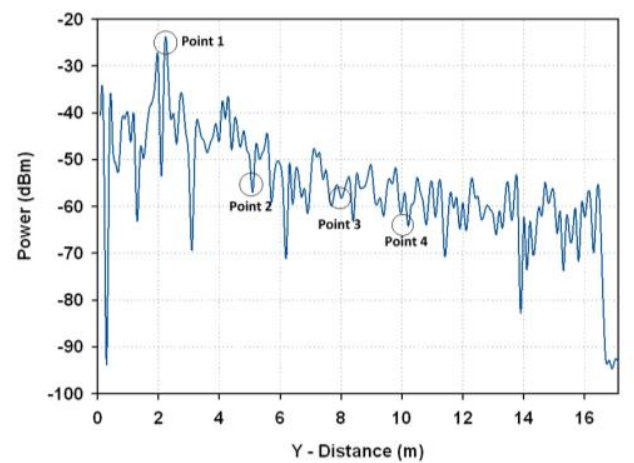

Fig. 17. Linear distribution of Received Power $(\mathrm{dBm})$ along the Y-axis, for $\mathrm{X}=1.35 \mathrm{~m}$ and $\mathrm{Z}=1.1 \mathrm{~m}$, for the metallic articulated bus.

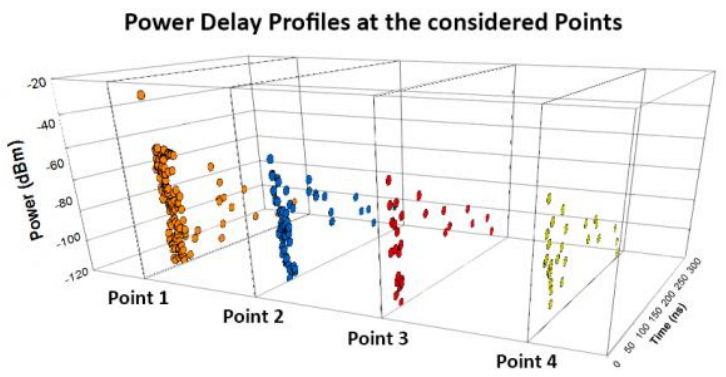

Fig. 18. Power Delay Profiles for the four considered points selected in Fig. 12.

These points have been chosen because of the different distances they have with the transmitter and the different multipath variability of each of them, as shown in Fig. 18. The cumulative distribution function $(\mathrm{CDF})$ of the power delay profiles shown in Fig. 18 has been computed and compared against Rayleigh distribution, which is commonly used to describe small-scale fading in indoor environments [34].

The probability density function (PDF) of a Rayleigh distributed random variable is given by

$$
p(r)=\frac{r}{\sigma^{2}} \exp \left(-\frac{r^{2}}{2 \sigma^{2}}\right)
$$

where $r$ is the magnitude of the received power, and $\sigma$ is the standard deviation of the multipath propagation. The CDF of Rayleigh distribution is obtained via integration over the PDF. 
Fig. 19 shows the actual flat fading statistics for the selected points and its fits with Rayleigh distributions. By analyzing Fig. 19 it can be seen that when increasing the transmitterreceiver separation distance, the standard deviation of multipath propagation decreases. This is due to the fact that since the distance has increased, the components contributing to the multipath propagation are more attenuated and more of them fall below the noise threshold, and therefore are not computed. Point 3 and Point 4 have a lower number of data due to the greater distance with the transmitter than the other considered points. Note that the small-scale analysis have been done with the power delay profiles shown in Fig. 18, and only the values higher than the noise threshold level have been considered.

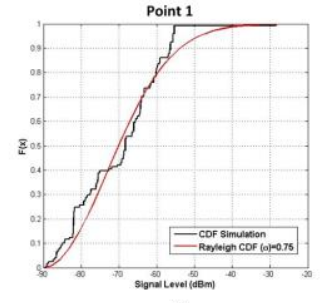

(a)

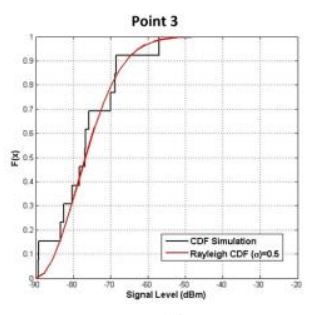

(c)

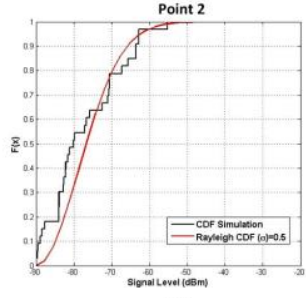

(b)

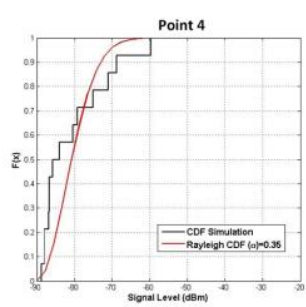

Fig. 19. Cumulative distribution functions for different points of the scenario depicted in Fig. 4a and its matching with Rayleigh distribution.

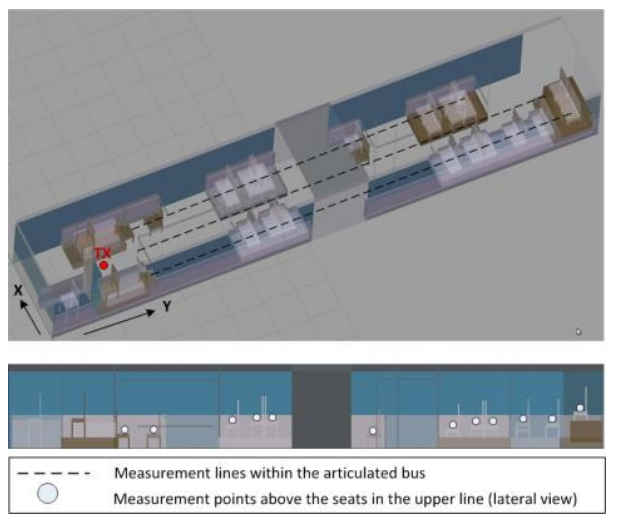

Fig. 20. Measurement points within the metallic articulated bus model.

\section{MEASUREMENT RESULTS}

In order to validate the results previously obtained, measurements in real urban buses have been obtained. These results provide assessment in wireless channel behavior, in order to perform adequate radio planning for deployment of embarked wireless systems, which will be developed in the following sub-section. Moreover, the analysis of received power levels within the urban bus scenario provides the required information in order to estimate current consumption levels for different transceiver operation modes, as will described in this section. A transmitter antenna, connected to a signal generator at $2.4 \mathrm{GHz}$ has been located at coordinates $(\mathrm{X}=1.35 \mathrm{~m}, \mathrm{Y}=2.03 \mathrm{~m}, \mathrm{Z}=1.10 \mathrm{~m})$ corresponding to the entrance of the bus, with a transmission power of $-10 \mathrm{dBm}$. The signal generator is a portable Agilent N1996A and the spectrum analyzer is an Agilent N9912 Field Fox. The antennas used are ECOM5-2400 from RS, both omnidirectional antennas. Fig. 20 shows the location for the transmitter in the model created for the metallic articulated bus. Measurements have been performed along the three dashed lines depicted in Fig. 20. In the central line, measurement points have been taken every meter at a height of 1.10 meters. For the lateral measurement lines, the bottom picture of Fig. 20 shows the measurement points above the seats, for different heights depending of the morphology of the buses. Similar measurements along the three lines have been performed for the rigid bus.

\section{A. Ray Launching Validation}

Figures 21 and 22 show the comparison between simulation and results for the measurement points performed along the three lines for the metallic articulated bus (Fig.21) and for the rigid bus (Fig. 22) models. Measurements were performed with $100 \mathrm{MHz}$ bandwidth at $2.4 \mathrm{GHz}$ frequency. The measurement time at each point was 60 seconds, and the value of received power represented by each point is the higher peak of power shown by the spectrum analyzer for the considered bandwidth. The received power values estimated by simulation have been obtained for the same spatial samples as the real measurements, considering the corresponding cuboid in the three-dimensional mesh of cuboids in which the scenarios have been divided.

The mean error between simulation and measurements for the metallic articulated bus is $0.67 \mathrm{~dB}$ with a standard deviation of $0.45 \mathrm{~dB}$, whereas for the rigid bus the mean is $0.88 \mathrm{~dB}$ with a standard deviation of $0.99 \mathrm{~dB}$, showing good agreement and validating previous simulations results.

\section{B.Wireless Sensor Network Deployment}

Radiochannel impact under real operating conditions is analyzed on an 802.15.4 WSN of 7 Wapsmote nodes deployed in zigzag along the bus, and a gateway in charge of data collection (Fig. 23). Nodes communicate, using channel 0x12 $(2.435-2.440 \mathrm{GHz})$, with a transmission power of $1 \mathrm{~mW}$ and are placed according to the locations in which passengers would be located, since this is potentially the most complex scenario. Network configuration, in terms of number and location of nodes, takes into account previous radioplanning estimations (to grant compliance with sensitivity thresholds in the complete indoor vehicular scenario) as well as capacity requirements considering the processing capabilities of ZigBee transceivers. In order to minimize energy consumption, wireless devices communicate following a space filling curve (SFC), which provides efficient network traversal. SFCs ensure passage through all nodes without doing twice through the same node. Messages travel from one node (\#i) to its successor (\#(i+1)) such that each node of the network just receives and transmits a single message (from its processor to its successor). The initiator node (\#1) periodically issues a message to its successor without receiving any message, while the gateway $(\mathrm{GW})$ receives messages without 
sending any. This avoids collisions and nodes only send those messages that are strictly necessary, ensuring minimal battery consumption. If a message loss occurs in a certain round, the message does not progress along the chain and the round is not completed. We assume that information is gathered often, so it is more profitable to wait for the next round than trying to recover the message lost. Message reception is not acknowledged at reception. The GW triggers a chain rebuilding process whenever a certain period of time is elapsed and no message is received. Fig. 24 presents a brief scheme of the algorithm.
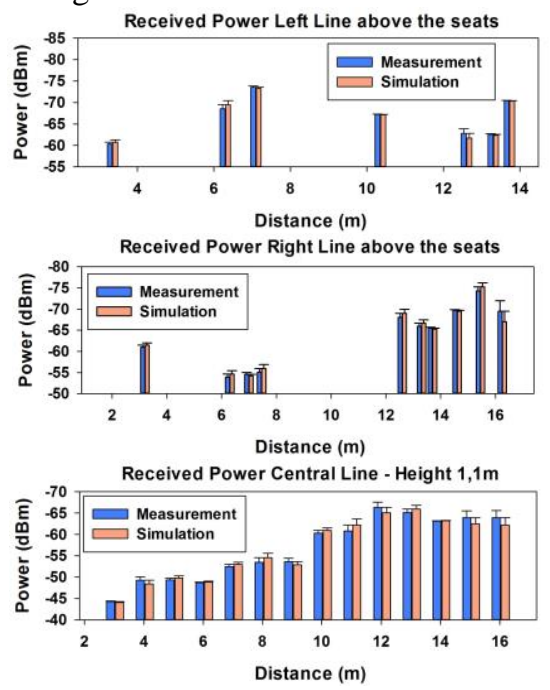

Fig. 21. Simulation versus measurements for $2.4 \mathrm{GHz}$ in the metallic articulated bus (top) left line (middle) right line (bottom) central line of the bus.
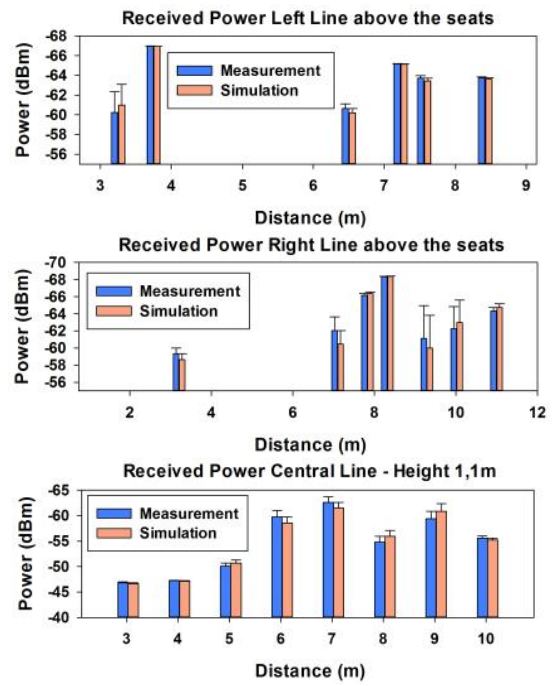

Fig. 22. Simulation versus measurements for $2.4 \mathrm{GHz}$ in the rigid bus (top) left line (middle) right line (bottom) central line of the bus.

Measurements are performed in batches of 10,000 send packet command iterations. The values given by the Received Signal Strength Indicator (RSSI) from the power circuit embedded in the wireless sensor are compared with spectrum analyzer measurements for the metallic articulated bus, providing some differences between them. Example values for position 2 and 6 are shown in Table VI. The mean value for the difference between measurements and RSSI values for the seven locations of nodes is around $2 \mathrm{~dB}$. The power offset (sensor vs. spectrum analyzer) is due to inaccuracies inherent to the embedded power detection circuits of the WSN motes, which motivated the use of a calibrated generator and a portable spectrum analyzer for the measurement validation previously presented.

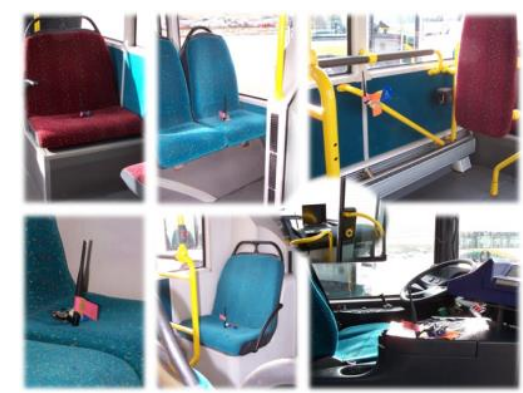

Fig. 23. Location of the wireless sensor network nodes within the bus.

In the experimental setup, node \#1 sends a message every 100 milliseconds. Although the payload of the message can include any type of information (temperature, humidity, etc. ) in our case we include RSSI levels of each node and their battery value, enabling trace analysis and network observation in terms of message loss and battery consumption. Information is aggregated at each node as the message travels through the different nodes of the chain. 29,751 rounds are initiated, while 29,558 rounds are successfully completed (98\% success rate). Table VII summarizes the number of rounds accomplished by type of vehicle and the success rates obtained. Although the distribution of messages lost by node is very heterogeneous for the three types of buses, it should be noted that the absolute number of messages lost is negligible regarding the 193 messages lost after initiating 29,751 iterations (0.65\%).

Intermediate node
Loop
message=receive();
data=senseData();
aggregateData(message, data); $_{\text {send(node }}$ (message); $_{\text {, }}$,
Gateway
Loop
result=select(node ${ }_{7}$, timer);
if (result $>0)\{$
message $=$ receive();
send2DB $($ db, message);
\} else rebuildChain();

\section{Initiator}

Setup

buildChain();

Loop

sleep(period);

data $=$ senseData(); message=buildMessage(data); send(node 2 ,message);

Fig. 24. Algorithm scheme.

TABLE VI

COMPARISON MEASUREMENTS VS. RSSI VS. SIMULATION

\begin{tabular}{cccc}
\hline \hline Node & Spectrum analyzer & RSSI & $\begin{array}{c}\text { 3D Ray Launching } \\
\text { Simul }\end{array}$ \\
\hline Rx 2 & $-42.57 \mathrm{dBm}$ & $-41.83 \mathrm{dBm}$ & $-42.32 \mathrm{dBm}$ \\
Rx 6 & $-40.64 \mathrm{dBm}$ & $-40.85 \mathrm{dBm}$ & $-40.53 \mathrm{dBm}$ \\
\hline \hline
\end{tabular}

The analysis of the RSSI values obtained at each node for each vehicle is depicted in Fig. 25. Node \#1 is not considered since it is the chain initiator and therefore, the only node that does not receive any message. Differences between maximum and minimum RSSI values for a given node can reach up to $30 \mathrm{~dB}$, depending on the type of vehicle considered. For the articulated bus with higher metallic content, the maximum and 
average RSSI values are closer to each other, while in the articulated bus with lower metallic content, minimal and average RSSI values are closer. In both cases, standard deviations are small $(2.3 \mathrm{~dB}$ vs. $1.7 \mathrm{~dB})$. The rigid bus has a maximum deviation of $23 \mathrm{~dB}$ and standard deviations are also small, with a maximum value of $1.3 \mathrm{~dB}$.

TABLE VII

NUMBER OR ROUNDS ACCOMPLISHED BY TYPE OF VEHICLE AND SUCCESS RATE

\begin{tabular}{cccc}
\hline \hline & \multicolumn{2}{c}{ ROUNDS } & \\
\cline { 2 - 3 } & Completed & Initiated & RATE \\
\cline { 2 - 3 } Articulated less metallic & 9,947 & 10,000 & $99.47 \%$ \\
Articulated more metallic & 9,636 & 9,751 & $98.21 \%$ \\
Rigid bus & 9,975 & 10,000 & $99.75 \%$ \\
\hline Total & 29,558 & 29,751 & \\
\hline \hline
\end{tabular}
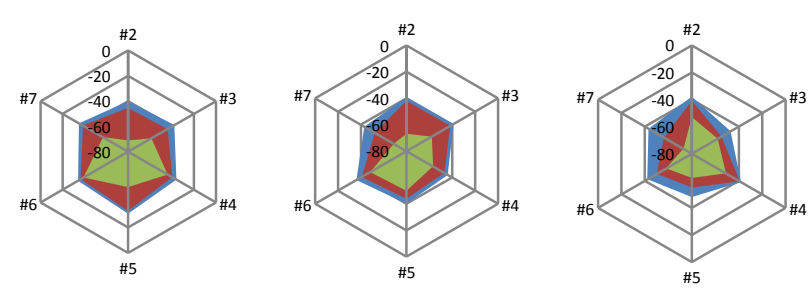

" Maximum $₫$ Average $\llbracket$ Minimum

Fig. 25. Distribution of RSSI values for the rigid bus (left), articulated bus more metallic (middle) and articulated bus less metallic (right).

As previously stated, the estimation of received power levels can be employed in order to analyze transceiver power consumption as a function of network topology. Therefore, this information can be used in order to optimally deploy the WSN, by following the coverage regions described initially in section III, by calculating current consumption levels in the full simulation volume. This procedure provides specific results, inherent to the scenario under analysis. Waspmote v1.1 nodes have been employed for the experimental setup, which exhibit a consumption of $15 \mathrm{~mA}$ when switched on, $55 \mu \mathrm{A}$ while sleeping (sleep and deep sleep) and $0.07 \mu \mathrm{A}$ when hibernating. Battery voltage varies from 3.3 to $4.2 \mathrm{~V}$ (see Fig. 26), while transmission power used is $1 \mathrm{~mW}$ and sensibility $92 \mathrm{dBm}$. We have performed 10,000 rounds per vehicle (except for the articulated more metallic bus, 9751) obtaining the results summarized in Table VIII. We consider a round completed by the system whenever all the nodes receive, aggregate their information and transmit the messages correctly from one side to the other (lossless communication). Similarly, we consider a round completed by node whenever this node has successfully received from its predecessor, aggregated its information and transmitted the corresponding message to its successor. Finally, we consider a round initiated each time the initiator node (\#1) sends a message and initiates the chain. These terms allow us to evaluate the effective consumption per node, and the average consumption per round of the system, and then estimate the effective longevity of the network. Table VIII reports the battery consumption, in terms of microvolts, for each node and scenario. Nodes communicate (non-beacon enabled mode of IEEE 802.15.4) following a chain structure where node \#i communicates directly to \#(i+1). Each node measures its battery voltage and the RSSI value of the last message received and sends them to the forward node of the chain. Node \#1 starts the chain communication and the rest of nodes just answer to messages sent by its predecessor. When a node \#i receives a message from its antecessor, it measures its battery level and the RSSI value of the received message and sends it to its successor $(\#(\mathrm{i}+1))$. The aim is to minimize WSN energy consumption, considering the impact of the scenario topology on network deployment, as well as the characterization of packet loss rate and energy consumption per node in order to adjust both communication protocol and network topology to improve the longevity of the network. We measure battery depletion by node and iterations performed. We then calculate the average battery consumption by node, by dividing the difference between the maximum and minimum battery values $(\mu \mathbf{V})$ obtained by the number of iterations initiated, completed by the node or completed by the system. The lowest consumption values correspond to node \#2 when considering the articulated buses, and node \#1 when considering the rigid bus. Generally, higher consumption values are observed at the central nodes of the buses, owed to multipath propagation, since a higher number of messages are received by nodes implying higher processing consumption. Consumption values increase as distance between nodes increases.

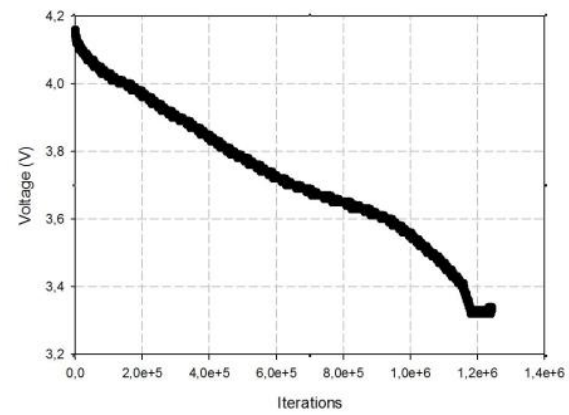

Fig. 26. Battery depletion.

TABLE VIII

BATTERY CONSUMPTION BY EACH NODE OF THE NETWORK

\begin{tabular}{|c|c|c|c|c|c|c|c|c|}
\hline \multirow{2}{*}{ Vehicle } & \multirow{2}{*}{$\begin{array}{c}\text { Battery } \\
\text { consumption } \\
(\mu \mathrm{V})\end{array}$} & \multicolumn{7}{|c|}{ Node } \\
\hline & & $\# 1$ & $\# 2$ & $\# 3$ & $\# 4$ & $\# 5$ & $\# 6$ & \#7 \\
\hline \multirow{3}{*}{ 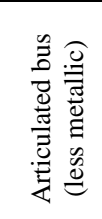 } & $\begin{array}{l}\text { Completed by } \\
\text { system }\end{array}$ & 6.48 & 0.64 & 13.62 & 9.08 & 4.54 & 19.45 & 3.89 \\
\hline & $\begin{array}{l}\text { Completed by } \\
\text { node }\end{array}$ & 6.45 & 0.64 & 13.56 & 9.04 & 4.52 & 19.42 & 3.88 \\
\hline & Initiated & 6.45 & 0.64 & 13.54 & 9.03 & 4.51 & 19.35 & 3.87 \\
\hline \multirow{3}{*}{ 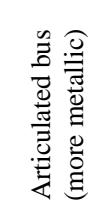 } & $\begin{array}{l}\text { Completed by } \\
\text { system }\end{array}$ & 4.01 & 1.33 & 10.71 & 7.36 & 3.34 & 6.02 & 4.68 \\
\hline & $\begin{array}{l}\text { Completed by } \\
\text { node }\end{array}$ & 3.96 & 1.32 & 10.59 & 7.29 & 3.31 & 5.97 & 4.68 \\
\hline & Initiated & 3.96 & 1.32 & 10.58 & 7.27 & 3.30 & 5.95 & 4.63 \\
\hline \multirow{3}{*}{ 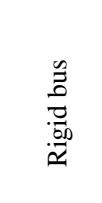 } & $\begin{array}{l}\text { Completed by } \\
\text { system }\end{array}$ & 2.58 & 3.23 & 5.17 & 4.52 & 3.23 & 3.23 & 3.23 \\
\hline & $\begin{array}{l}\text { Completed by } \\
\text { node }\end{array}$ & 2.58 & 3.22 & 5.16 & 4.52 & 3.23 & 3.23 & 3.23 \\
\hline & Initiated & 2.58 & 3.22 & 5.16 & 4.51 & 3.22 & 3.22 & 3.22 \\
\hline
\end{tabular}


The average consumption shows low deviation of tens of microvolts for all the scenarios considered, so we can conclude that the consumption difference between initiated and completed rounds is not significant due to the high success rate obtained. However, the difference among scenarios is relevant (see Table IX), since the average battery consumption for the articulated less metallic bus is more than twice the consumption for the rigid bus (from 3.6 to $8.2 \mu \mathrm{V}$ ). Some multipath components are treated as multiple individual messages causing higher energy consumption since a higher number of packets are received and they must be processed. The vehicle length also determines the battery consumption since the longer the vehicle is, the higher battery consumption is observed. The explanation may be the greater proximity of nodes among them.

TABLE IX

Average Battery Consumption of the WSN

\begin{tabular}{|c|c|c|c|c|}
\hline \multirow[b]{2}{*}{ Vehicle } & \multicolumn{2}{|c|}{ Average $(\boldsymbol{\mu V})$} & \multicolumn{2}{|c|}{ Deviation $(\mu \mathbf{V})$} \\
\hline & Initiated & $\begin{array}{l}\text { Completed } \\
\text { by system }\end{array}$ & Initiated & $\begin{array}{l}\text { Completed } \\
\text { by system }\end{array}$ \\
\hline Articulated less metallic & 5.29308 & 5.35625 & 3.04374 & 3.00784 \\
\hline Articulated more metallic & 8.20276 & 8.24647 & 6.43949 & 6.40536 \\
\hline Rigid bus & 3.59446 & 3.60347 & 0.12910 & 0.12878 \\
\hline
\end{tabular}

The deviation in the battery consumption is significantly lower in the rigid bus, probably due to its shortest length, and therefore due to a lower impact of multipath attenuation and reduced by the distance. The greater battery consumption observed at the articulated less metallic vehicle (8.20276 vs. $5.29308 \mu \mathrm{V}$ ) may be caused by a higher presence of carbon fiber on the body of the vehicle, which prevents the wireless signal transmission through the vehicle body, causing multipath propagation. The different battery consumptions at node \#1 (the chain initiator) are mainly given by greater signal confinement experienced at the articulated buses. As battery consumption remains constant with respect to transmission, the increased consumption observed refers to a greater reception of packets due to multipath propagation.

\section{CONCLUSIONS}

In this work, the influence of topology and morphology of different types of urban buses for wireless links operating at $2.4 \mathrm{GHz}$ frequency has been analyzed. Different models of specific buses have been developed for the in-house developed 3D ray launching code and simulation results have been obtained. Simulations have been done with the random presence of human beings inside the buses and without them, showing a significant influence in the signal attenuation in the case of considered persons. In order to validate simulations, measurement results in real buses have been obtained, showing good agreement and clearly indicating the topological and morphological impact in the received power values. In addition, the statistical analysis of simulation results considering large-scale and small-scale fading has been performed, providing coherent results for typical indoor environments. Furthermore, a WSN has been programmed and deployed in order to analyze topological impact with overall system performance. The use of the deterministic 3D ray launching algorithm allows the optimization in the location of transceivers and hence the determination of the final network topology. Consequently, the overall system performance can be enhanced, reducing power consumption as well as nondesired interference levels, which are critical parameters in the case of Wireless Sensor Networks, due to inherent energy restrictions.

\section{ACKNOWLEDGMENTS}

The authors wish to acknowledge the financial support of projects TEC2013-45585-C2-1-R and TIN2011-28347-CO102 , funded by the Spanish. The authors wish also to acknowledge the support and collaboration of the Mancomunidad de la Comarca de Pamplona responsible for the bus fleet and also of the bus operator company, TCC.

\section{REFERENCES}

[1] W. Xiang, Y. Huang, S. Majhi, "The Design of a Wireless Access for Vehicular Environment (WAVE) Prototype for Intelligent Transportation System (ITS) and Vehicular Infrastructure Integration (VII)," IEEE $68^{\text {th }}$ Vehicular Technology Conference.

[2] R. P. S. Padmanaban, L. Vanajakshi, S. C. Subramanian, "Estimation of Bus Travel Time Incorporating Dwell Time for APTS Applications," IEEE Intelligent Vehicles Symposium, 2009, pp. 955-959.

[3] W. Chen, L. Chen, Z. Chen, S. Tu, "WITS: A Wireless Sensor Network for Intelligent Transportation System," International Multi-Symposiums on Computer and Computational Sciences, 2006, vol. 2, pp. 635-641.

[4] H. Tao, W. Liu, S. Ma, "Intelligent Transportation Systems for Wireless Sensor Networks based on ZigBee," International Conference on Computer and Communication Technologies in Agriculture Engineering (CCTAE), 2010, vol. 2, pp. 396-399.

[5] M. Tubaishat, P. Zhuang, Q. Qi, Y. Shang, "Wireless sensor networks in intelligent transportation systems," Wireless Communication and Mobile Computing, 2009, vol. 9, $\mathrm{n}^{\circ} 3$, pp. 287-302.

[6] H-Y. Zhou, G. de Sousa, J-P. Channet, K-M. Hou, J-J. Li, C. de Vaulx, M. Kara, "An Intelligent Wireless Bus-Station System Dedicated to Disabled, Wheelchair and Blind Passengers," IET Int. Conference on Wireless, Mobile and Multimedia Networks, 2006, pp. 1-4.

[7] T. P. Quoc, M.C. Kim, H.K. Lee, K.H. Eom, "Wireless Sensor Network apply for the Blind U-bus System," International Journal of $U$-and $e$ Service, Science and Technology, 2010, vol. 3, $\mathrm{n}^{\circ} 3$.

[8] G. Baudoin, O. Venard, G. Uzan, A. Rousseau, Y. Benabou, A. Paumier, J. Cesbron, "How can blinds get information in Public Transports using PDA? The RAMPE Auditive Man Machine Interface," $8^{\text {th }}$ Proceeding AAATE, Lille, 2005, pp. 304-16.

[9] G. Lavanya, W. Preethy, A. Shameem, R. Sushmitha, "Passenger BUS Alert System for Easy Navigation of Blind," International Conference on Circuits, Power and Computing Technologies, 2013.

[10] F. Bellens, F. Quitin, F. Horlin, P. De Doncker, "Channel Measurements and MB-OFDM Performance Inside a Driving Car," International Conference on Electromagnetics in Advanced Applications, Torino, Italy, September 14-18, 2009.

[11] N. Alam, A.G. Dempster, "Cooperative Positioning for Vehicular Networks: Facts and Future", IEEE Transactions on Intelligent Transportation Systems, Vol. 14, No 4, pp. 1708-1717, December 2013

[12] Jin Zhou, C. L. Philip Chen, Long Chen, and Wei Zhao, "A UserCustomizable Urban Traffic Information Collection Method Based on Wireless Sensor Networks", IEEE Transactions on Intelligent Transportation Systems, Vol. 14, No. 3, pp. 1119 - 1128, September 2013

[13] Ye Zhu, Anil Vikram, and Huirong Fu, "On Topology of Sensor Networks Deployed for Multitarget Tracking", IEEE Transactions on Intelligent Transportation Systems, Vol. 15, No. 4, pp. 1489 - 1498, August 2014

[14] T. Tsuboi, J. Yamada, N. Yamauchi, M. Nakagawa, T. Maruyama, "UWB Radio Propagation for Intra Vehicle Communications," International Conference on Ultra Modern Telecommunications \& Workshops, St. Petersburg, Russia, October 12-14, 2009. 
[15] C. U. Bas, S. C. Ergen, "Ultra-wideband Channel Model for Intravehicular Wireless Sensor Networks Beneath the Chassis: From Statistical Model to Simulations," IEEE Transactions on Vehicular Technology, 62, 1, pp. 14-25, January 2013.

[16] M. Peter, W. Keusgen, A. Kortke, M. Schirrmacher, "Measurement and Analysis of the $60 \mathrm{GHz}$ In-Vehicular Broadband Radio Channel", IEEE 66th Vehicular Technology Conference (VTC), Baltimore, MD, USA, Sept. 30 2007-Oct. 3, 2007.

[17] D. W. Matolak, A. Chandrasekaran, "Aircraft intra-vehicular channel characterization in the $5 \mathrm{GHz}$ band", Integrated Communications, Navigation and Surveillance Conference, Bethesda, USA, 5-7 May, 2008.

[18] N. Moraitis, P. Constantinou, "Radio Channel Measurements and Characterization inside Aircrafts for In-Cabin Wireless Networks", IEEE $68^{\text {th }}$ Vehicular Technology Conf., Calgary, Canada, 21-24 Sept. 2008.

[19] A. Skrebtsov, A. Burnic, Dong Xu, A. Waadt, P. Jung, "UWB applications in public transport", International Conference on Communications, Computing and Control Applications (CCCA), Hammamet, Tunisia, 3-5 March, 2011.

[20] N. R. Diaz, J. E. J. Esquitino, "Wideband channel characterization for wireless communications inside a short haul aircraft", IEEE 59th Vehicular Technology Conference (VTC), vol.1, 17-19 May, 2004.

[21] W. Dong, G. Liu, L. Yu, H. Ding, J. Zhang, "Channel Properties of indoor part for high-speed train based on wideband channel measurement", 5th International ICST Conference on Communications and Networking in China (CHINACOM), 2010, pp. 1-4.

[22] H. J. Song, J. S. Colburn, H. P. Hsu, R. W. Wiese, "Development of Reduced Order Model for Modeling Performance of Tire Pressure Monitoring System," IEEE 64th Vehicular Technology Conference, Montreal, Canada, September 25-28, 2006.

[23] M. Iskander, Z. Yun, "Propagation prediction models for wireless communication systems," IEEE Transactions on Microwave Theory and Techniques, 2002, vol. 50, issue 3, pp. 662-673.

[24] G. Gennarelli, G. Riccio, "A uapo-based model for propagation prediction in microcellular environments," Progress In Electromagnetics Research B, 2009, vol. 17, pp. 101-116.

[25] H. W. Son, N. H. Myung, "A deterministic ray tube method for microcellular wave propagation prediction model," IEEE Transactions on Antennas and Propagation, 1999, vol. 47, issue 8, pp. 1344-1350.

[26] H. Song, H. Wang, K. Hong, L. Wang, "A novel source localization scheme based on unitary esprit and city electronic maps in urban environments," Progress in Electromagnetics Research, 2009, vol. 94, pp. 243-262.

[27] A. Tayebi, J. Gómez, F. de Adana, O. Gutierrez, "The application of arrival and received signal strength in multipath indoor environments," Progress in Electromagnetics Research, 2009, vol. 91, pp. 1-15.

[28] L. Azpilicueta, M. Rawat, K. Rawat, F. Ghannouchi, F. Falcone, "Convergence analysis in deterministic 3D Ray Launching radio channel

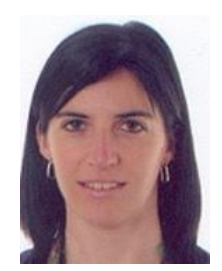

Leire Azpilicueta received her Telecommunications Engineering Degree from the Public University of Navarre (UPNA), Pamplona, Spain, in 2009. In 2010 she worked in the R\&D department of RFID Osés as radio engineer. In 2011, she obtained a Master of Communications held by the Public University of Navarre. She is currently pursuing the Ph.D. degree in telecommunication engineering. Her research interests are on radio propagation, mobile radio systems, ray tracing and channel modeling.

Peio López Iturri received his Telecommunications Engineering Degree from the Public University of Navarre (UPNA), Pamplona, Navarre, in 2011.

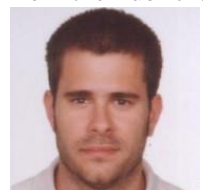
Since then he has been working in the 'FASTER' research project at UPNA. He obtained a Master of Communications in 2012, held by the UPNA and he is currently pursuing the Ph.D degree in telecommunication engineering. His research interests include radio propagation, modeling of radio interference sources and mobile radio systems. estimation in complex-environments," The Applied Computational Electromagnetics Society Journal, vol. 29, n 4, April 2014.

[29] L. Azpilicueta, F. Falcone, J. J. Astrain, J. Villadangos, I. J. García Zuazola, H. Landaluce, I. Angulo, A. Perallos, "Measurement and modeling of a UHF-RFID system in a metallic closed vehicle," Microwave and Optical Technology Letters, vol. 54, Issue 9, pp. 21262130.

[30] A. Moreno, I. Angulo, A. Perallos, H. Landaluce, I. J. G. Zuazola, L. Azpilicueta, J. J. Astráin, F. Falcone, J. Villadangos, "IVAN: Intelligent Van for the Distribution of Pharmaceutical Drugs," Sensors, 2012, vol. 12, pp. 6587-6609.

[31] J. A. Nazábal, P. Iturri López, L. Azpilicueta, F. Falcone and C. Fernández-Valdivielso, "Performance Analysis of IEEE 802.15.4 Compliant Wireless Devices for Heterogeneous Indoor Home Automation Environments," International Journal of Antennas and Propagation, Hindawi Publishing Corporation.

[32] S. Led, L. Azpilicueta, E. Aguirre, M. Martínez de Espronceda, L. Serrano, F. Falcone, "Analysis and Description of HOLTIN Service Provision for AECG monitoring in Complex Indoor Environments," Sensors, 2013, vol. 13, Issue 4, pp. 4947-4960.

[33] P. L. Iturri, J. A. Nazábal, L. Azpilicueta, P. Rodriguez, M. Beruete, C. Fernández-Valdivielso and F. Falcone, "Impact of High Power Interference Sources in Planning and Deployment of Wireless Sensor Networks and Devices in the $2.4 \mathrm{GHz}$ frequency band in Heterogeneous Environments," Sensors, 2012, vol. 12, issue 11, pp. 15689-15708.

[34] E. Aguirre, J. Arpón, L. Azpilicueta, S. de Miguel, V. Ramos and F. Falcone, "Evaluation of electromagnetic dosimetry of wireless systems in complex indoor scenarios within body human interaction," Progress In Electromagnetics Research B, vol. 43, pp. 189-209.

[35] Balanis, Constantine A. Advanced engineering electromagnetics. Vol. 205. Wiley New York, 1989.

[36] E. Aguirre, J. Arpón, L. Azpilicueta, S. de Miguel, V. Ramos, F. Falcone, "Evaluation of Electromagnetic Dosimetry of Wireless Systems in Complex Indoor Scenarios with human body interaction," PIER B, vol. 43, pp. 189-209, 2012.

[37] T. S. Rappaport, Ed., Wireless Communications: Principles and Practice. Englewood Cliffs, NJ: Prentice Hall, 2001.

[38] W. Dong, G. Liu, L. Yu, H. Ding, J. Zhang, "Channel properties of indoor part for high-speed train based on wideband channel measurement", Communications and Networking in China (CHINACOM), 2010, $5^{\text {th }}$ International ICST Conference.

[39] K. Siwiak, "Radiowave propagation and antennas for personal communications," Artech House, Inc., 1998.

[40] V. Weerackody, "Characteristics of a simulated fast fading indoor radio channel," $43^{\text {rd }}$ IEEE Vehicular Technology Conf., 1993, pp. 231-235.

[41] W.C. Jakes, "Microwave Mobile Communications," Wiley \& Sons, 1993.

[42] [Online] Available: https//www.libelium.com/development/waspmote.

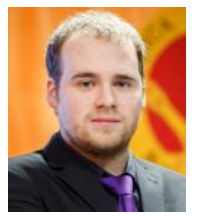

Erik Aguirre received his Technical Telecommunications Engineering Degree (2010), M.Sc. Degree in Communications (2012) and $\mathrm{PhD}$ (2014) at the Universidad Pública de Navarra (UPNA) in Spain. His research area is complex electromagnetic scenarios, wireless system analysis andhuman body interaction with wireless systems.

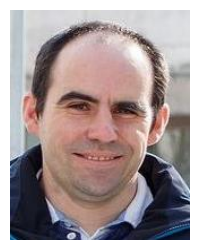

José Javier Astrain received his Telecommunications Engineering Degree (1999) and PhD in Computer Science (2004), both at the Public University of Navarre (Spain) where he works as lecturer. His current research interests concern wireless sensor networks, distributed systems and ontology driven algorithms. He was awarded with the Premio Talgo 2012 for Technological Innovation.

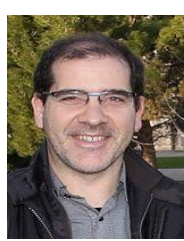

Jesús Villadangos received his degree in Physics from the Universidad del País Vasco (Spain) in 1991 and his PhD in Communications Engineering (1999) at the Public University of Navarre (Spain) where he becomes Associate Professor in 2000. He has worked in several R\&D projects supported by National and International entities. He is coauthor of three spanish patents, and more than 20 
international papers. He was awarded with the Premio Talgo 2012 for Technological Innovation. His research interests are software engineering, distributed algorithms, vehicular networks, and ontology driven algorithms.

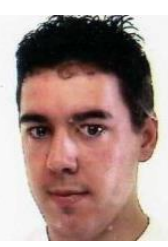

Cristobal Zubiri received his Telecommunications Engineering Degree from the Public University of Navarre (UPNA), Pamplona, Navarre, in 2013. He is currently working in the analysis of vehicular wireless networks.

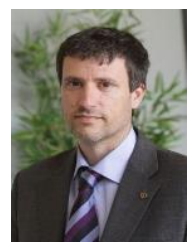

Francisco Falcone (M05, SM09) received his Telecommunication Engineering Degree (1999) and $\mathrm{PhD}$ in Communication Engineering (2005), both at the Public University of Navarre in Spain. From 1999 to 2000 he worked as Microwave Commissioning Engineer, SiemensItaltel. From 2000 to 2008 he worked as Radio Network Engineer, Telefónica Móviles. In 2009 he co-founded Tafco Metawireless, From 2003 to 2009 he was also Assistant Lecturer at UPNA, becoming Associate Professor in 2009. His research area is artificial electromagnetic media, complex electromagnetic scenarios and wireless system analysis. He has over 400 contributions in journal and conference publications. He has been recipient of the CST Best Paper Award in 2003 and 2005, Best PhD in 2006 awarded by the Colegio Oficial de Ingenieros de Telecomunicación, Doctorate award 2004-2006 awarded by UPNA, Juan Lopez de Peñalver Young Researcher Award 2010 awarded by the Royal Academy of Engineering of Spain and Premio Talgo 2012 for Technological Innovation. 